\title{
Achieving a pro-public transport agenda in South Africa - the challenge for middle income countries
}

\author{
A. Shaw \\ Development Bank of Southern Africa
}

\begin{abstract}
This paper explores constraints to the delivery of improved urban public transport in South Africa (SA). Improving and integrating public transport systems within middle-income countries such as SA is often difficult. (Middleincome countries have income ranging between $\$ 745$ and $\$ 9,360$ per capita (World Bank, 2004). Cities in such countries are fast growing, have high levels of car ownership, often have relatively developed public transport systems with a mix of informal and formal operators.) Operators are challenged by a shift in the status quo. The intensity of growth in traffic and private car usage makes congestion a growing constraint to the free flow of public transport vehicles. Government has limited funding for infrastructure improvements and often exerts limited day-to-day control over what occurs within the public transport system.

Recent shifts in policy in SA have focussed on a new vision for public transport, yet little if any change is discernable on the ground. The paper explores some of the reasons why SA has struggled to implement this new vision. The paper concludes by drawing certain lessons from other middleincome countries that may have application both in SA and elsewhere.

Keywords: public transport, South Africa, city, integrated, minibus taxi, bus, rail, middle-income countries.
\end{abstract}

\section{Introduction}

Democratic elections in 1994 in SA heralded an era of both economic and social reform. Government policy quickly shifted to addressing the needs of the poor. Improved public transport, although identified as a critical area of social 
delivery, has changed little and some may argue has worsened since 1994. Patronage by bus and rail has declined, regulation of informal minibus taxi operators is ineffective and recent spatial development is more reflective of the suburban sprawl associated with private car use than the needs of public transport users.

Car growth has increased phenomenally in the last decade, due in part to the success of the economy, rising incomes and a quickly expanding middle class. Public transport has become the mode of the poor and a recent national transport user survey reflects wide-ranging dissatisfaction with what is on offer.

\section{Characteristics of South African urban public transport}

The sprawling character of cities and the legacy of land use planning under Apartheid have characterised the form of public transport in SA cities. Public transport is described as chaotic in visitors' guides to our cities [1]. There is an almost active attempt by the operators of different modes to discourage integration. Government has been ineffectual in improving the character of the system. The transition to democracy has been followed by a burgeoning middleclass and hence the market for private cars has increased dramatically. In 2005 SA recorded its highest ever year-on-year growth in new car sales of $25 \%$ [2]. Car trips account for $37 \%$ of all motorised trips in metropolitan areas. In cities such as Johannesburg average travel times have increased by $17 \%$ over the 8 years up until 2003. This increase is a reflection of growing and endemic peak period congestion.

Minibus-taxis, an informal paratransit mode with a capacity of roughly 15 passengers per vehicle, provide for $70 \%$ of public transport trips in metropolitan areas. They compete intensively amongst themselves and with formal modes of transport, particularly rail. This form of competition is regarded as 'destructive' [3,4] as most routes are overtraded and the cost efficiency of larger capacity scheduled modes such as rail and bus is reduced. This necessitated a heavy reliance on subsidy by these formal modes. Minibus-taxi drivers seldom receive fixed salaries but rather accrue the excess of a basic daily minimum which is paid to the owner of the vehicle. This form of incentivisation coupled with intense competition creates a short-termism in the way in which the industry is run. It forces informal operators to flout local traffic regulations in a desperate search to collect new passengers and maximise revenue for the day [5]. Money is seldom set aside for recapitalisation of vehicles and although there is intense competition most routes are controlled by associations which charge joining fees or ongoing support fees. Whilst it is difficult to assert that such payments amount to extortion these organisations do represent a form of market control that is unlike a traditional cartel [5]. A cartel may seek to protect its members by restraining market access in the interest of existing traders. The motivation on many routes is not to restrict market entry but to rely on market entry as a revenue generator.

Informal public transport is a characteristic of many developing cities. Jitney's in Cairo, the collective in Buenos Aires, jeepney's in Manila, the dolmus 
in Istanbul and the Matatu of Nairobi. All operate smaller vehicles than traditional busses. They do not adhere to timetables and although they offer a fixed route structure they quickly react to shifts or changes in patterns of demand. Khayesi [6] provides an excellent insight into the matatu operations of Nairobi and identifies a number of characteristics identical to that of the SA minibus-taxi. The socio-economic characteristics in the matatu sector are one of 'intense struggle for an economic niche'. This differentiates the sector form more well understood forms of competitive behaviour associated with the formal sector. The players in the matatu industry ... "have evolved their own sets of rules and structures to secure economic survival and maintain control". These are characterised by "deeply entrenched route-based cartels" that may resort to violence if intimidated by other cartels or by government. "Entry of a new matatu owner into the business is not a free market choice but rather a negotiation with key stakeholders ... based on a wide range of social, political and economic variables ... including and exorbitant goodwill fee" and many features which resemble "mafia like behaviour". 'Matatu drivers violate traffic rules with impunity' and this is of great concern to the government of Kenya. There is evidence to suggest that these characteristics are shared to a greater or lesser degree by most of the world's informal public transport providers.

Commuter rail services operate in all of SA's largest cities. Services are provided by Metrorail, a national state-owned company. The characteristic of most of these operations is to link the townships with central business districts or the older large industrial areas of the city. (Townships are large, dense and poor residential areas created during Apartheid or the colonial period. These areas are often characterised by their distance from the centre of most cities. With increased urbanisation such areas have increased in population size.) Competition by mini-bus taxi operators is intense along rail corridors. Rapid changes in SA urban form continue to marginalise the access which commuter rail provides. The rail system is often characterised as dilapidated and because it is slow, has low fares and often requires long walking distances in order to be accessed is often the mode of choice of those who are unable to afford anything else. Many cities in SA advocate enhancing the quality and reach of rail services often referring to 'rail as the backbone of the public transport system'. This is despite a decline in urban rail patronage of over $30 \%$ over the last two decades (1983 to 2003) [7].

At a strategic level bus services are provided to serve two niche markets. The first is suburban city services provided by buses owned in most cases by municipalities. They tend to serve the sprawling suburban areas and not the denser more public transport dependent townships. The quality of such services has declined and continuing congestion hampers any ability to make these services a viable alternative to private car. Although cities such as Johannesburg have renewed their fleet and altered there route structure, such services remain poorly integrated with other forms of public transport. The second market which busses serve is long routes between relatively isolated industrial and commercial centres and far flung townships or former homeland areas. Such routes are generally provided by the private sector through either negotiated or tendered 
contract. All such routes require subsidy and due to the nature of demand and the distance of operation compete less intensively with minibus-taxi than does rail.

Two characteristics typify the SA urban public transport system. The first is the impact of Apartheid. Most services sustain the same pattern as was defined for them prior to 1994, and although no-longer racially segregated they remain unintegrated. The second is the mix of highly regulated, mostly government owned services competing with unsubsidised informal services. Figure 1 shows the shift occurring in SA cities, reflected in this case by data for Cape Town, which shows the growing dominance of minibus-taxi as a mode of choice amongst users. Other cities show even higher levels of minibus taxi usage with $73 \%$ of all work based public transport trips in Johannesburg made by this mode [8].

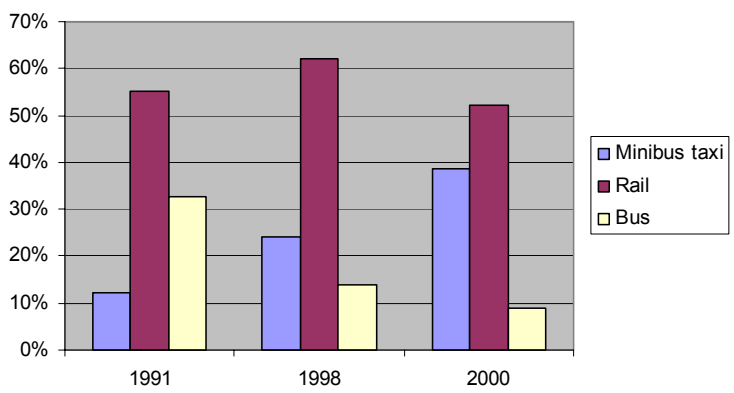

Figure 1: $\quad$ Shifts in market share for public transport modes in Cape Town.

\section{The South African urban public transport vision}

In 1996 Government published the first White Paper on National Transport Policy since the transition to democracy. The document is emphatic in its policy response to serve the needs of the public transport dependent. A key strategic objective is "to promote the use of public transport over private car travel, with the goal of achieving a ratio of 80:20 between public transport and private car usage" [9]. In Johannesburg this ratio was 60:40 in 1995 worsening to 47:53 by 2002 [8].

The White Paper process was followed in 1998 by a 18-month strategic initiative entitled "Moving South Africa" (MSA) [10]. This was an attempt to identify the critical factors that needed to be addressed in implementing the highlevel strategic vision posed by the White Paper. In the urban transport context three critical actions were identified.

\subsection{Densification of transport corridors}

This required a reversal of Apartheid's dispersed land use patterns and the concentration of higher intensity development along the dominant public transport corridors, as shown in Figure 2. 


\subsection{Optimisation of modal economics and the public transport service mix}

This required a re-orientation of the planning and operation of public transport to promote the mode that offered the best cost/service trade-off to customers. High capacity rail would serve the high-volume corridors $(40,000$ passengers or more per day, per direction). Corridors with moderate ridership (10,000 to 40,000 passengers per day) would be served by road based public transport with dedicated infrastructure to provide priority over private car. Low ridership corridors (fewer than 10,000 passengers per day) would operate in mixed traffic but with attention given to enhanced infrastructure along these routes.

\subsection{The improvement of firm-level performance}

This required setting and regulating the 'rules of the game' for operators. It included improving contract management for formal operators, effectively regulating and enforcing a permit system for minibus taxis' and improving the overall dissemination of subsidy.
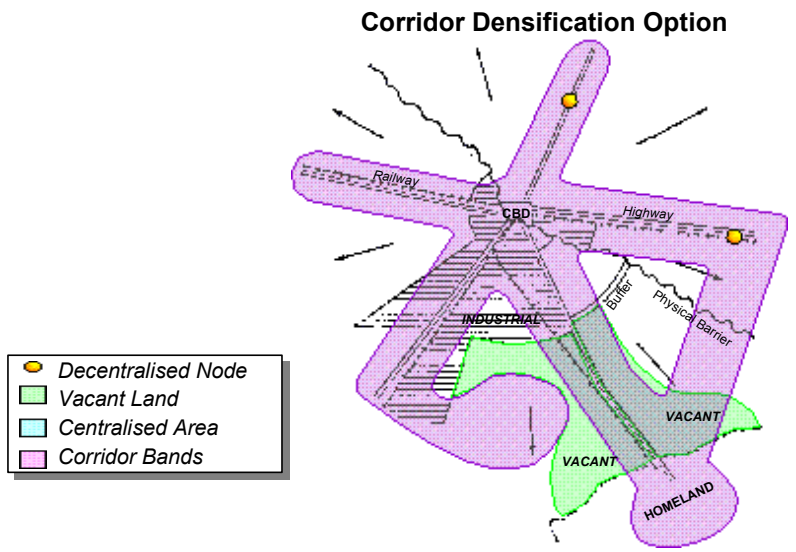

Figure 2: Representation of the corridor vision for land use and public transport [10].

\section{Implementing the vision}

At the time MSA was being set up the National Land Transport Transition Act (NLTTA) was already in draft form. It was enacted with changes in 2000 and reflected the new strategic emphasis provided by MSA. It is now the core institutional and regulatory mechanism for addressing challenges in urban public transport. The Act creates the regulatory mechanism for addressing the abovementioned 'rules of the game'. It also creates 'Transport Authorities' as local-level agents responsible for planning and implementing public transport. These are modelled closely on those of Germany and the UK [11]. A planning 
process is created which emphasises the need to integrate the modes and identify along which corridors and routes different modes would be most suitable. Unfortunately, this planning process is both complex and overly rigid and consideration is being given to its simplification.

The planning process has also achieved little on the ground. Metropolitan public transport has not improved and there is increasing discontent amongst users, as demonstrated in Table 1.

Table 1: $\quad$ Dissatisfaction with public transport - Metro areas [12].

\begin{tabular}{|c|c|c|c|}
\hline Mode & Rail & Bus & Taxi \\
\hline $\begin{array}{l}\text { Percentage of } \\
\text { users dissatisfied }\end{array}$ & $45 \%$ & $27 \%$ & $52 \%$ \\
\hline $\begin{array}{l}\text { Most important } \\
\text { reasons for } \\
\text { dissatisfaction }\end{array}$ & $\begin{array}{l}\text { - Overcrowding on } \\
\text { trains } \\
\text { - Poor security on } \\
\text { train and to and } \\
\text { from station } \\
\text { - Long distance } \\
\text { between train } \\
\text { station and home }\end{array}$ & $\begin{array}{l}\text { Poor facilities at } \\
\text { stops, e.g. } \\
\text { shelters } \\
\text { - Low frequency of } \\
\text { services in off- } \\
\text { peak } \\
\text { - Poor security on } \\
\text { bus and to and } \\
\text { from stops }\end{array}$ & $\begin{array}{ll}\text { - } & \text { Poor safety from } \\
\text { accidents } \\
\text { - } & \text { Poor facilities at } \\
\text { stops/ranks } \\
\text { - Vehicles not } \\
\text { roadworthy }\end{array}$ \\
\hline
\end{tabular}

The reasons for dissatisfaction are insightful. They demonstrate both poor overall service quality and a lack of integration. Overcrowding, lack of safety and security and poor quality stops are important reasons for unhappiness. Long distances to reach railway stations indicate the poor integration of rail with feeder modes. Low frequency of bus services underlies the characteristic of this mode (outside of the municipal bus services) as a niche operator on low demand long-distance routes, rather than as a mover of large volumes of passengers on the dominant corridors. A lack of roadworthiness and the high risk of traffic accidents are characteristic of minibus taxis. Poor quality of stops and stations demonstrate a lack of a conducive environment in which to easily and safely make inter-modal transfers, further retarding opportunities for integration. $78.2 \%$ of bus users, $78.7 \%$ of minibus taxi users and $45.4 \%$ of rail users do not make a transfer from one vehicle to another in undertaking the average work trip. This underlies a complex spider web of unintegrated routes, many at very low frequency, and often competing directly with one another.

The MSA vision has had little if any impact on the system and when assessing performance against the actions identified in 1998 the following conclusions may be drawn.

\subsection{Densification of transport corridors}

Some densification has occurred in SA cities but is based on intensified car use rather than patterns of corridor densification to enhance the use of public transport. Low income housing continues to be placed at the periphery of large 
urban concentrations and is based on 'one house one plot' policy which discourages multi-storey development in immediate proximity to high-volume public transport corridors. It also promotes the de-densification of the townships and reduction in average household size [13]. Mixed use development has intensified, but again this has been more supportive of intensified car use than public transport. In suburban areas it has further marginalised the access potential of public transport users to mixed-use developments which have occurred in suburban areas rather than along the dominant public transport corridors.

\subsection{Optimisation of modal economics and the public transport service mix}

The NLTTA provides the means to plan more effectively to enhance the modal economies of public transport. Often however, the interpretation of this planning process has motivated large-scale capital intensive proposals such as new or improved railway lines and tram systems, whilst paying little attention to users' actual day-to-day choice of minibus taxi as the preferred mode. The challenge in the planning process of displacing informal modes, often through a recognition that the higher capacity bus and rail modes need to carry a much greater proportion of passengers particularly in the high demand corridors, is not addressed. The implication is that the outcome of the planning process is often not achievable. Firstly, because of the capital intensive nature of the funding requirements, which Government has not provided for. Secondly, as a consequence of the challenges of reducing the role of smaller vehicle in the public transport system without providing a strategy for addressing the political challenges of who owns and operates what and under what conditions.

\subsection{The improvement of firm-level performance}

This setting of the 'rules of the game' for operators of public transport has incurred intense debate. The permit or 'operating licence' system is controlled at Provincial level. Many minibus-taxi operators have failed to register their vehicles within the numerous deadlines given by Government. The implication is that the 'operating licence' system is ineffectual. The fact that there is no active on-the-ground enforcement intensifies the problem and reduces the value of the regulatory process. Improved firm-level performance for formal modes has also been problematic. They continue to compete with informal operators, have no incentive to integrate with other modes, and incentives to promote better and more efficient service delivery are no better than before. Much of the bus system continues to be provided by 'negotiated contracts' or by state owned bus services, despite the recommendation that the 'competitive contract system' should be enhanced. Rail services continue to receive a 'deficit subsidy' and have no incentive to promote greater efficiency or better customer service. The quality of formal services, particularly rail continues to decline. Lower levels of farebox revenue and less subsidy than is necessary to sustain the quality and reliability of rail services results in a continued decline in market share. 


\section{Failure to deliver effective public transport}

Why has SA been so ineffective in its agenda to improve the use of public transport? The question is at least partly answered by a shift to private car. This is as much as a consequence of poor quality public transport as it is a result of rapid shifts in the income of the middle class. It has also a result of a failure by Government to control the competitive behaviour of informal providers on one hand and to invest in and introduce greater competition to the formal public transport market on the other. A lack of funding to support the implementation of planning, improve infrastructure quality and enhance integration has contributed to the problem.

\section{Lessons from other middle-income countries}

Some middle-income cities (by no means all) have fared better than those in SA. They have achieved this by pro-active implementation of a quality integrated public transport system. Without exception, this has required direct government intervention in the provision of infrastructure, the regulation of operators and as overseer of the provision of services.

Middle income cities with successful approaches seem to be concentrated in South America. Curitiba, is the best and perhaps most flouted example [14]. Yet, the order and control which planners where able to exert in Curitiba is unlikely to be either acceptable or possible with the constitutional, regulatory and institutional environment and with the spatial legacy of SA cities. Bogotá is another often quoted example of success. It represents something of a cross-over where many of the lessons learnt in Curitiba have been applied to a city with an existing more traditional pattern of urban development [15]. It is thus perhaps a more realistic example of what is possible.

As far as lessons learnt are concerned, three categories of intervention are discernable; in infrastructure, through involving or co-ordinating the private sector and through changes in regulation and enforcement.

\subsection{Infrastructure interventions}

Investing in dedicated road infrastructure which directly supports public transport is now commonplace. Lessons emerge from Curitiba and Essen in Germany where busways where first piloted. More recent applications can be found in Porto Allegre, Taipai, Delhi, Santiago and Istanbul. High passenger turnover requires that these systems receive little or no subsidy although it may be necessary for Government to build the infrastructure. All such systems have the characteristic of a high-demand corridor with various levels of regulation and integration between operators. Menckhoff [15] identifies two busway options, the direct service and the integration option. The first promotes a service where vehicles converge from various origins and use the busway for the highest demand portion of the route. The second uses high-capacity, often articulated buses on the high demand busway with interconnections to smaller vehicle 
services at transfer stations. Like most integrated forms of public transport this option is likely to be characterised by through-ticketing and revenue sharing between operators.

\subsection{Involving and co-ordinating the private sector}

ITDP [16] makes it clear that in ... "a city where only private vehicles and minibuses exist, introducing large buses on major arterials is the first step towards efficiencies of a trunk and feeder system". Infrastructure investments such as exclusive busways usually follow on from this by separating the buses from mixed traffic in areas where traffic intensity is high. In most cities this sequential process has been the norm, with some cities actively promoting the achievement of both at the same time.

A holistic approach to involving different operators is also necessary. Profitability of feeder routes in Bogotá and other cities has been found to be low and the higher profitability of the line-haul component has necessitated a crosssubsidy between these operators [16].

PPPs are now commonplace in the development of such integrated systems. The busway system in San Salvador was developed through a PPP and funded by the IFC [16]. Concessions for the operation of rail based systems are also now popular, particularly for new rail links. Evidence suggests that involving the private sector in rail service operation brings the benefit of enhanced efficiency and reliability and a stronger customer focus [17].

\subsection{Changes in regulation and enforcement}

Latin American and Indian experience reinforces the need for regulation of private operators [16]. In all cases linking a license to the operator of a route and almost always regulating and enforcing at a city-level.

Lessons in implementing busways identify opportunities to use dedicated road infrastructure as an incentive to get buy-in from operators. Busways may be implemented within an existing system of small operators, such as in Jakarta, where operators choose to remain in or outside of the system. Becoming part of the system implies meeting certain regulatory pre-conditions [18].

\section{How could South Africa change its approach?}

Government in SA may have been overly optimistic. The vision was to make radical shifts in a short space of time. Clearly this has not worked. Incremental change may offer a more manageable approach than attempting rapid change on a number of fronts. The high-demand corridors should become the focus for incremental change. These corridors are easily ring-fenced and relatively smallscale interventions can impact on a large number of public transport users. Incremental approaches may be considered for two levels of high demand corridor, those where rail is already in place and those where road based modes predominate. 
High-demand rail corridors are crying out for greater levels of innovation in service delivery. Two options may be appropriate to changing the delivery model for these corridors. In both cases the corridor or the city rail network should be ring fenced and separated from the national railway company. The first option is to create a local transport company in which equity is shared between traditional railway company, city transport authority and the minibus taxi operators already providing feeder services to stations. In the second option, which could well be combined with the first, a PPP model is created. The model would seek to design a rail concession incorporating incentives for the promotion of; innovation in service delivery, improvements in the quality of fixed and movable assets and where appropriate rail extensions which would improve the coverage of rail.

On those high-demand corridors where road-based modes predominate there is an opportunity to integrate public transport services by working together with existing operators rather than relying entirely on enforcement to achieve a changed approach. In Jakarta busway infrastructure was introduced as an incentive for integration amongst operators thus creating a model without preconditions, such as; which vehicle types, what form of regulation and what level of integration must be in place before creating appropriate supporting infrastructure. Infrastructure in combination with approaches such as through ticketing can therefore be used to create the incentive for attaining other objectives, such as improved regulation, integration and the priority of public transport over private car. This is particularly true in the case of creating necessary buy-in from the minibus taxi sector. Again city-level approaches are likely to work best, both in terms of planning for and setting up such a corridor initiative.

Clearly both approaches require resources, both financial and technical. The financial resources could well be integrated with Government's already farreaching infrastructure strategy, known as ASGISA. Technical resources and innovation could be promoted though creating scope for pilot projects, funded at the outset by national Government. These should not be based on detailed planning with no resources for implementation as has been the case in the past. Planning should be limited and the focus of investment should be on implementation. Cities such as Delhi, have devoted some resources to planning but have a strongly focussed implementation agenda [16]. A further important lesson is that the overwhelming number cities which have successfully implemented enhancements in public transport have high degrees of local control and autonomy over planning, regulation and enforcement of operators.

\section{References}

[1] SouthAfrica.info, Transport in Johannesburg.

[2] Econometrix, Yet again vehicle sales for December surprise with their strength, Econometrix Newsletter No 0606/0196, $10^{\text {th }}$ Jan 2006.

[3] Fourie, L.J., Rethinking the formalisation of the minibus taxi industry in South Africa, Dissertation submitted in partial fulfilment of MSc (Eng), University of Pretoria, 2003. 
[4] Shaw, A., Fundamental restructuring of the planning, management and operation of urban public transport networks, CSIR, Pretoria, 1998.

[5] Khosa, M., The travail of travelling: Urban transport in South Africa: 1930 - 1996, Transport Reviews 18:1, Taylor and Francis, London, 1998.

[6] Khayesi, M., Struggle for Socio-Economic Niche and Control in the Matatu Industry in Kenya, DPMN Bulletin, Volume IX, Number 2, May 2002.

[7] Development Bank of Southern Africa, The DBSA infrastructure barometer, Economic Infrastructure in South Africa, DBSA, Midrand, 2006.

[8] City of Johannesburg, Integrated Transport Plan, 2003-2008, 2004.

[9] Department of Transport, White Paper on National Transport Policy, Pretoria, South Africa, 1996.

[10] Department of Transport, Moving South Africa: A Transport Strategy for 2020, Report and Strategic Recommendations, Pretoria, South Africa, 1998.

[11] Department of Transport, An introduction to transport authorities, Pretoria, South Africa, 2001.

[12] Department of Transport, National Household Travel Survey - 2003, Technical Report, Pretoria, South Africa, 2005.

[13] South African Cities Network, State of the cities report - 2004, Johannesburg, 2005.

[14] Friberg, L., Innovative Solutions for Public Transport; Curitiba, Brazil, Article published in Sustainable development International, 2000.

[15] Menckhoff, G., Latin American experience with bus rapid transit, Annual Meeting, Institute for Transport Engineers, Melbourne, August 2005.

[16] ITDP, Institutional and Regulatory Options for Delhi's High Capacity Bus System: Lessons from International Experience, May 2004.

[17] Gomez-Ibanez, J., Railroad reform: An overview of options, Paper presented at the Conference for Railway Reform, Madrid, Sep 2004

[18] Hook, W., Institutional and regulatory options for bus rapid transit in developing countries, Institute for Transportation and Development Policy, New York, 2005. 